Yüzüncü Y1 Üniversitesi
Tarim Bilimleri Dergisi

Araştırma Makalesi (Research Article)

\title{
Dihaploid Kestane Kabağı (Cucurbita maxima Duch.) Çeşit Adaylarının Konya İlinde Verim ve Meyve Kalitesinin Belirlenmesi
}

\author{
Musa SEYMEN ${ }^{* 1}$ \\ ${ }^{1}$ Selçuk Üniversitesi, Ziraat Fakültesi, Bahçe Bitkileri Bölümü, 42031, Konya, Türkiye \\ ${ }^{1}$ https://orcid.org/0000-0002-2742-137X \\ *Sorumlu yazar e-posta: mseymen@selcuk.edu.tr
}

\section{Makale Bilgileri}

Geliș: 02.03.2020

Kabul: 04.05.2020

Online Yayinlanma 30.06.2020

DOI: 10.29133/yyutbd.697267

\section{Anahtar kelimeler}

Agronomi,

Cucurbitaceae

Dihaploid,

Kestane kabağı,

Lokasyon
Öz: Kestane kabağı ülkemizde başta tatlı olmak üzere, reçel, marmelat, pasta ve turşu olarak insan beslenmesinde kullanılmaktadır. Kestane kabakları yetiştirildiği bölgenin ekolojik koşullarından etkilenmekte, verim ve meyve kaliteleri önemli düzeyde değişkenlik göstermektedir. Bu çalışmada ülkemizde ticari çeşit olarak tescil edilen ve ekonomik değere sahip olan Arıcan-97 ve Balkız çeşitleri ile dihaploidizasyon tekniği ile elde edilen iki adet dihaploid kestane kabağı çeșit adayının İç Anadolu bölgesinin en geniş ovasına sahip, Konya ovasında verim ve meyve özellikleri ortaya koyularak adaptasyon yetenekleri belirlenmeye çalışılmışıtır. Sunulan çalışma dihaploid kestane kabağı çeşit adaylarının ticari çeşitlerle karşılaştırılarak performanslarının belirlendiği ilk çalışma özelliğindedir. Çeşit ve çeşit adaylarında verim ve meyve kalitesi ölçümlerinde önemli farklılıklar bulunmuştur. En yüksek verim Arıcan $97(2350 \mathrm{~kg} / \mathrm{da})$ çeşidinden ve DH-6 (2325 kg/da) çeşit adayından elde edilmiştir. En fazla bitki başına meyve sayısı aynı çeşitlerden sırası ile 1.74 ve 1.50 adet olarak elde edilmiştir. En yüksek SÇKM ve pH DH-8 çeşit adayından elde edilirken, yapılan tat testi sonucunda ticari çeşitler daha yüksek puan almıştır. Sonuç olarak, Konya Ovasında Arıcan 97 önemli bir ticari çeşit olarak karşımıza çıksa da çeşit adayı olarak nitelendirilen DH-6 genotipi verim ve meyve kalitesi yönünden önemli sonuçlar vermiştir. Bu durumda DH-6 genotipinin Arıcan 97'ye alternatif bir çeşit olarak değerlendirilebileceği öngörülmüştür.

\section{Determination of Yield and Fruit Quality of Dihaploid Pumpkin (Cucurbita maxima Duch.) Variety Candidates in Konya Province}

\section{Article Info}

Received: 02.03.2020

Accepted: 04.05.2020

Online Published 30.06.2020

DOI: $10.29133 /$ yyutbd.697267

\section{Keywords}

Agronomy,

Cucurbitaceae,

Dihaploid,

Pumpkin,

Location
Abstract: Pumpkin is used in our country as a dessert, jam, marmalade, cake and pickle in human nutrition. It is affected by the ecological conditions of the region where they are grown, their yield and fruit quality vary significantly. In this study, adaptation abilities of Arıcan-97 and Balkız cultivars, which are registered as commercial cultivars in our country and have economic value, and the dihaploid genotypes obtained from the dihaploidization technique, in Konya plain with the widest plain of Central Anatolia region, and their adaptation capabilities tried to be determined. The presented study is the first study feature where the performance of dihaploid pumpkin variety candidates is compared with commercial cultivars. Significant differences were found in yield and fruit quality measurements in cultivars and dihaploid pumpkin variety. The highest yield was obtained from Arıcan 97 (2350 kg da ${ }^{-1}$ ) cultivar and DH-6 (2325 kg da ${ }^{-1}$ ) dihaploid genotype. The maximum number of fruits per plant was 1.74 and 1.50 , respectively, of the same varieties. While the highest TSS and $\mathrm{pH}$ are obtained from DH-8 cultivar candidates, the commercial cultivars got higher scores after 
the taste test. As a result, although Arıcan 97 appears as an important commercial cultivar in Konya Plain, the DH-6 genotype, which is described as a candidate for variety, has yielded important results in terms of yield and fruit quality. In this case, it is predicted that DH-6 genotype can be evaluated as an alternative cultivar to Arican 97.

\section{Giriş}

Cucurbitaceae familyası içinde bulundurduğu yaklaşı 120 cins ve 800 tür ile yazlık sebzelerin en büyük familyasıdır (Tzortzakis ve ark., 2018). Cucurbitaceae familyası dünyanın her yerinde yetiştirilen, yazlık kabak (Cucurbita pepo L.), kışlık kabaklar (Cucurbita maxima Duch. ve Cucurbita moschata Duch.), kavun (Cucumis melo), karpuz (Citrullus lanatus), hiyar (Cucumis sativus) ve acur (Cucumis melo var. flexuosus) gibi ekonomik getirisi yüksek türlerin yanı sıra kudret narı (Momordica charantia L.), su kabağ (Lagenaria vulgaris L.) ve lif kabağı (Luffa actangua L. Roxb) gibi türleri de içinde barındırmaktadır. Kabak, kavun, karpuz ve hıyar gibi türlerin meyveleri taze veya pişirilerek tüketilmesinin yanı sıra, bazı türlerin olgun tohumları insan beslenmesinde doğrudan ve dolaylı olarak kullanılmaktadır (Seymen ve ark., 2019). Ülkemizde tatlı yapımında kullanılan ve bal kabağı olarak bilinen kışlık kabaklar kestane kabağı içinde yer almaktadır. Ülkemizde krem ve açık yeşil tonlarında kabuk rengine sahip, meyve eti turuncu, eliptik ve yuvarlak meyve şeklinde, dilimli ve 5-15 kg meyve ağırlığına sahip kestane kabakları bal kabağı olarak değerlendirilmektedir (Aslan ve ark., 2019).

Cucurbita türleri, antibakteriyel, antidiyabetik, antihipertansiyon, antitümör, immünomodülatör, antihipolkolesterolemi, antiparaziter, antienflamatuar ve antalgik gibi çeşitli terapötik özelliklerle sahiptir (Tzortzakis ve ark., 2018). Meyve posasında önemli miktarda karotenoid, klorofil, toplam fenol ve vitamin B6, C, E, K, tiamin ve rivoflavin, ayrica makro ve mikro mineraller (K, P, Se ve Fe) bulunur (Blanco-Díaz ve ark., 2015; Adubofuor ve ark., 2016; Yeşil, 2019). C. maxima meyvesinden elde edilen suda, çözünür polisakaritler de önemli bir antioksidan içeriği olduğu saptanmıştır (Nara ve ark., 2009). Diğer taraftan kabak tohumları kanser hastalıklarında önemli bir ajan olan skualen maddesini içermektedir (Dessì ve ark., 2002; Rabrenovi ve ark., 2014). Özellikle kolon, meme ve prostat kanserine karşı önemli etkilerinin olduğu tespit edilmiştir (Medjakovic ve ark., 2016). Bal kabakları başta tatlı olmak üzere, reçel, pasta, marmelat ve turşu olarak insan beslenmesinde kullanılmaktadır.

Dünyada yaklaşı 1.1 milyar ton sebze üretimi gerçekleşmektedir. Bu üretimde 104 milyon ton karpuz, 75 milyon ton hiyar, 27 milyon ton kavun ve 27 milyon ton kabak üretimi yer almaktadır (FAO, 2018). Kabakgiller toplamda 255 milyon ton'luk (yaklaş1k \% 25) üretim değeri ile dünya sebze üretiminde önemli bir paya sahiptir. Ülkemizde ise 2018 y1lı verilerine göre 616777 ton kabak üretimi-gerçekleşmiştir. Bu üretimin 474.527 tonunu yazlık kabaklar, 87207 tonunu kışlık kabaklar, 55.043 tonunu çerezlik kabaklar oluşturmuştur (TÜIK, 2018).

Balkaya ve ark. (2011), yapmış oldukları çalışmada, ülkemizde kışlık kabak türlerine ait genetik kaynakların toplanması, seleksiyonu ve tarımsal özelliklerinin üzerine yapılan çalışmaların yeterli olmadığını bildirmişlerdir. Ülkemizde uzun yıllardır Sakarya Mısır Araştırma Enstitüsü tarafından geliştirilen ve tescil edilen Arıcan-97 kestane kabağı ticari çeşit olarak değer bulmaktadır. Diğer taraftan aynı kurum tarafından Balkız ismi ile 2018 yılında yeni bir ticari çeşit piyasaya sürülmüsşür. Kestane kabağının ekonomik getirisinin düşük olmasından dolayı ülkemizde halen standart çeşitlerle ya da üretici kendi tohumluklarından üretim yapmaktadır. Kabaklar monoik çiçek yapısından dolayı yabanci tozlanan türlerdir. Yabanc1 tozlanma sonucunda mevcut genotiplerde genetik açılma yüksek oranda görülmektedir. Bu durum bir taraftan genetik çeşitliliği artırarak avantaj sağlasa da diğer taraftan yerel genotiplerin özelliklerinin değişmesine sebep olmaktadır (Babaoğlu ve Türkmen, 2017). Bundan dolayı standart meyve kalitesini yakalamak, verimi artırmak ve üretim bölgelerine adapte olabilecek çeşit ve çeşitleri geliştirmek önem arz etmektedir.

F1 hibrit sebze ıslahının ilk aşaması saf hatların elde edilmesidir ve bu süreç kabak gibi yüksek oranda yabancı tozlanan türlerde 8-10 yıl kadar sürmektedir. Bu süreç sonunda dahi \% 100 saf bir hattın elde edilmesi mümkün olamamaktadır. 
Ancak dihaploidizasyon adı verilen yöntem sayesinde \% 100 saf hatların eldesi 1-2 yıl gibi kısa bir sürede gerçekleştirilebilmekte, zaman, işgücü ve ıslahta ilerleme açısından büyük kazanımlar sağlanmaktadır. Ülkemizde yazlık ve kışlık kabak türlerinde gerek ışınlanmış polen (Kurtar ve ark., 2002; Berber, 2009; Kurtar ve ark., 2009; Kurtar ve Balkaya, 2010; Bektemur ve ark., 2014), gerek anter kültürü (Kurtar ve ark., 2016) ve gerekse ovül kültürü (Kurtar ve ark., 2018) yoluyla dihaploid bitkiler elde edilmiştir.

Kestane kabakları ekolojik faktörlerden etkilenmesi sonucunda bölgelere göre üretimde büyük farkl11ıklar ortaya çıkmaktadır. Yapılan çalışmada, ülkemizde ticari çeşit olarak tescil edilen ve ekonomik değere sahip olan Arıcan-97 ve Balkız çeşitleri ile dihaploidizasyon tekniği ile elde edilen iki adet dihaploid kestane kabağı çeşit adaylarının İç Anadolu bölgesinin en geniş ovasına sahip Konya ovasında verim ve meyve özellikleri ortaya koyularak adaptasyon yetenekleri belirlenmiştir.

\section{Materyal ve Yöntem}

Araştırma, 2019 yılı Mayıs-Ekim ayları arasında, Selçuk Üniversitesi, Ziraat Fakültesinin Konya ili Selçuklu ilçesi Sarıcalar köyünde bulunan Uygulama ve Araştırma Çiftliği'nde yürütülmüştür. Araştırmada materyal olarak dihaploidizasyon tekniği ile elde edilen iki dihaploid hat (DH-6 ve DH-8) ile ülkemizde ticari olarak yetiştirilen ve Sakarya Mısır Araştırma Enstitüsü tarafından tescil edilen Arıcan-97 ve Balkız çeşitleri kullanılmıştır (Şekil 1). Araştırma arazisinin yapılan toprak analizi sonucunda killi-tınlı yapıya sahip olduğu, organik madde yönünden fakir, bitki besin elementi yönünden azot ve fosforun yetersiz olduğu görülmüştür.
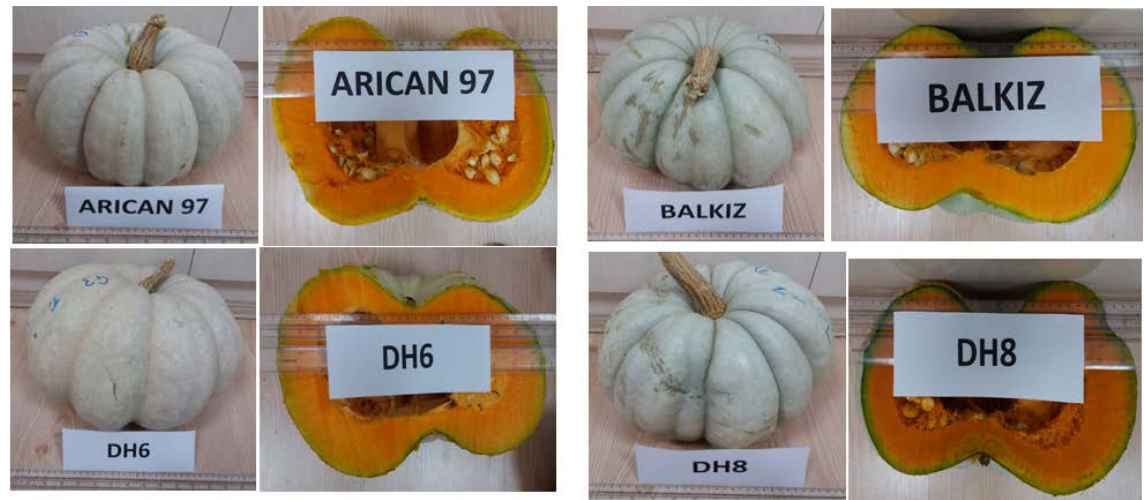

Şekil 1. Denemede kullanılan genotiplerin meyve görünümleri.

Araştırmada tohum ekimleri 20 Mayıs 2019 tarihinde yapılmış olup her çukura iki tohum ekilmiştir. Deneme tesadüf blokları deneme desenine göre 3 tekerrürlü olarak ve her tekerrürde 10 bitki olacak şekilde $3 \times 2$ metre aralık ve mesafelerle kurulmuştur. Bitkilerin sulanması için damla sulama sisteminden faydalanılmıştır. Deneme arazisinin ilk toprak işlemesinde, toprak analiz sonuçları da dikkate alınarak, dekara $15 \mathrm{~kg}$ hesabi ile taban gübresi olarak DAP (Diamonyum fosfat) gübrelemesi yapılmıştır. Fide çıkışları gerçekleştikten sonra fideler 2-3 yapraklı hale geldiğinde toprak işlenmiş ve her ocakta bir bitki kalacak şekilde seyreltme yapılmıştır. 10 Haziran 2019 tarihinde damla sulama sistemiyle her parsele dekara 1 lt hesabı ile NPK'lı sıvı organomineral gübre (Synergy) ve 2 lt olacak şekilde sıvı organik gübre (Evergreen Soil) ile azotlu gübre çözeltisi (Nitrosol) uygulanmıştır. 31 Kasım 2019 tarihinde meyvelerin hasatları yapılmıştır.

Meyveler hasat edilirken her parseldeki bitki sayısı (adet/parsel), meyve sayısı (adet/parsel) ve meyve ağırlıkları $(\mathrm{kg} /$ parsel) belirlenmiştir. Her parselden alınan 5 meyvede meyve eni $(\mathrm{cm})$, meyve boyu $(\mathrm{cm})$, meyve kabuk kalınlığı $(\mathrm{mm})$, çekirdek evi eni $(\mathrm{cm})$ ve çekirdek evi boyu $(\mathrm{cm})$ ölçülmüştür. Meyve robotu ile elde edilen meyve suyunda SÇKM ve $\mathrm{pH}$ değerleri okunmuştur. Meyvenin iki farklı yerinden renk tayin cihazı (Chroma Meter CR-400) ile meyve kabuk rengi ve meyve eti rengi değerleri $L^{*}, a^{*}$ ve b* cinsinden belirlenmiştir. Diğer taraftan her çeşit adayı, firında 35 dakika pişirilerek tat testi yapılmıştır. Tat testinde orta yaşın üstünde beş kadın ve beş erkek katılımcıdan 1-5 arasında (1-en kötü, 5-en iyi) puanlama yapılması istenmiştir. Her katılımcı birbirinden etkilenmemesi için ayrı ayrı puanlamaya alınmış ve verdikleri puanların ortalaması alınarak değerlendirme yapılmıştır. 
Araştırmada elde edilen verim ve meyve kalitesi değerleri JMP 10 bilgisayar paket programı kullanılarak \%5 önem seviyesine göre analiz edilmiş ve uygulamalar arasındaki farklar ortaya koyulmuştur.

\section{Bulgular ve Tartışma}

Yapılan çalışma sonucunda kestane kabağı çeşit ve çeşit adaylarının Konya şartlarında verim, meyve sayıS1, meyve ağırlığı, \% SÇKM ve $\mathrm{pH}$ değerlerinde önemli farklılıklar elde edilmiştir (Çizelge 1). Dekara verim incelendiğinde en yüksek verim Arıcan $97(2350 \mathrm{~kg} / \mathrm{da})$ çeşidinden ve DH-6 (2325 $\mathrm{kg} / \mathrm{da}$ ) çeşit adayından elde edilmiş ve istatistiksel anlamda aynı grup içerisinde yer almıştır. Aslan ve ark. (2019), yapmış oldukları çalışmada Arıcan 97 ticari çeşidinden ortalama 1.9 ton/da verim elde etmişler ve farklı lokasyonların verimi önemli derecede etkilediğini, lokasyonlardan 1.4-2.6 ton/da arasında verim elde ettiklerini bildirmişlerdir. Conti ve ark. (2015), İtalya'da yapmış oldukları çalışmada ortalama açık alandan 3 ton/da, sera yetiştiriciliğinde 4.1 ton/da meyve verimi elde etmişlerdir. Elde edilen verim değerlerinden de görüldüğü gibi ülkemizdeki yapılan çalışmalarda verimlerin düşük olduğu ve yüksek verimli çeşitlere ihtiyaç olduğu görülmektedir. Yapılan çalışmada yine aynı şekilde Arıcan 97 ve DH-6 sırası ile 1.74 ve 1.50 adet bitki başına meyve sayısı ile en yüksek meyve veren genotipler olmuştur. Aslan ve ark. (2019), kestane kabağ 1 genotiplerinden bitki başına 1.4-2.0 adet arasında meyve elde ederken, Conti ve ark. (2015), açık alanda 3.5 adet meyve elde etmişlerdir. Ortalama meyve ağırlığı bakımından DH-6 (10.54 kg), DH-8 (9.41 kg) ve Arıcan 97 $(8.99 \mathrm{~kg})$ en ağır meyveleri veren ve istatistiksel anlamda aynı grup içerisinde yer alan genotipler olmuştur. Aslan ve ark. (2019), aynı şekilde 5.8-8.1 kg arasında meyve ağırlıkları elde etmişlerdir. Elde edilen sonuçlar yapılan çalışmalarla örtüşmektedir. Suda çözünür kuru maddeye bakıldığında en yüksek kuru madde 13.23 ile DH-8 çeşit adayından elde edilmiştir. Diğer taraftan en yüksek pH 7.17 ile DH-8 ve Balkız genotiplerinden elde edilmiş̧ir. Farklı araştırmacılar bal kabaklarında suda çözünür kuru madde miktarının 7.5-13.0 arasında değiştiğini bildirmişlerdir (Balkaya ve ark., 2010; Ekincialp ve ark., 2016; Babaoğlu ve Türkmen, 2017; Aslan ve ark., 2019). Yapılan tat testi sonucunda elde edilen veriler incelendiğinde en yüksek değeri Arıcan 97 (4.4) çeşidi almıştır. Diğer taraftan dihaploid çeşit adayları ise en düşük puanları alan adaylar olmuştur.

Çizelge 1. Kestane kabağı çeşit ve çeşit adaylarının verim ve meyve kalite özellikleri

\begin{tabular}{lcccccc}
\hline $\begin{array}{l}\text { Çeşit ve } \\
\text { çeşit } \\
\text { adayları }\end{array}$ & $\begin{array}{c}\text { Dekara verim } \\
(\mathrm{kg} / \mathrm{da})\end{array}$ & $\begin{array}{c}\text { Bitki başına } \\
\text { meyve sayıs1 } \\
\text { (adet) }\end{array}$ & $\begin{array}{c}\text { Ortalama } \\
\text { meyve } \\
\text { ağırlığ }(\mathrm{kg})\end{array}$ & $\begin{array}{c}\text { briks }^{\mathrm{o}} \\
\text { SÇKM }\end{array}$ & $\mathrm{pH}$ & $\begin{array}{c}\text { Tat testi } \\
\text { değerleri }\end{array}$ \\
\hline Arıcan 97 & $2350 \mathrm{a}$ & $1.74 \mathrm{a}$ & $8.99 \mathrm{ab}$ & $10.63 \mathrm{~b}$ & $7.00 \mathrm{~b}$ & 4.4 \\
DH 8 & $1570 \mathrm{~b}$ & $1.08 \mathrm{~b}$ & $9.41 \mathrm{a}$ & $13.23 \mathrm{a}$ & $7.17 \mathrm{a}$ & 3.3 \\
DH 6 & $2325 \mathrm{a}$ & $1.50 \mathrm{a}$ & $10.54 \mathrm{a}$ & $8.5 \mathrm{~b}$ & $6.78 \mathrm{c}$ & 2.6 \\
Balkız & $1459 \mathrm{~b}$ & $1.13 \mathrm{~b}$ & $7.47 \mathrm{~b}$ & $9.0 \mathrm{~b}$ & $7.17 \mathrm{a}$ & 3.9 \\
\hline LSD \%5 & 478 & 0.27 & 1.89 & 2.53 & 0.15 & \\
\hline
\end{tabular}

*DH: Dihaploid

Araştırma sonucunda, kestane kabağı çeşit ve çeşit adaylarının meyve boyu ve meyve kabuk kalınlığında istatistiksel anlamda önemli farklar görülürken, meyve eni, çekirdek evi eni ve çekirdek evi boylarında istatistiki anlamda fark bulunmamıştır (Çizelge 2). Meyve boyu değerleri incelendiğinde DH-6 $(21.83 \mathrm{~cm})$, Arıcan $97(21.50 \mathrm{~cm})$ ve DH-8 $(21.33 \mathrm{~cm})$ çeşit ve çeşit adayları en yüksek meyve boyuna sahip olmuşlardır. Farklı bal kabağ 1 genotiplerinde Ferriol ve ark. (2004), 8.2 $66.0 \mathrm{~cm}$, Balkaya ve ark. (2010), 28-32 cm, Babaoğlu ve Türkmen (2017), 12-63 cm arasında meyve boyu değerleri elde etmişlerdir. Bal kabaklarında meyve boyunda büyük bir varyasyonun olduğu fakat elde edilen değerlerin ortalama bal kabağı boyutunda olduğu görülmektedir. DH-8 çeşit adayı (11.14 $\mathrm{mm})$ ve Arıcan 97 çeşidi $(9.78 \mathrm{~mm})$ en yüksek meyve kabuk kalınlığına sahip genotipler olmuştur. Balkaya ve ark. (2010), ortalama meyve kabuk kalınlığını $5.7 \mathrm{~mm}$ olarak bulmuştur. Aslan ve ark. (2019), kestane kabaklarında kabuk kalınlığının fazla olmasıyla dış zararlanmalardan daha az etkileneceğini, fakat kabuk kalınlığının ince olmasıyla meyve eti randımanının yüksek olacağını bildirmişlerdir. Bizim çalışmamızda elde ettiğimiz kabuk kalınlarının yüksek olmasının, muhafaza 
süresine olumlu etkisinin olacağ 1 düşünülmüştür. Diğer taraftan çeşit ve çeşit adaylarından 29.33$31.66 \mathrm{~cm}$ arasında meyve eni, 5.66-8.66 cm arasında çekirdek evi eni ve 20.00-23.33 cm arasında çekirdek evi boyu elde edilmiştir. Elde edilen sonuçlar Ferriol ve ark. (2004), Balkaya ve ark. (2010) ve Babaoğlu ve Türkmen (2017)'in sonuçları ile uyumluluk göstermektedir.

Çizelge 2. Kestane kabağı çeşit ve çeşit adaylarının meyve özellikleri

\begin{tabular}{lccccc}
\hline $\begin{array}{l}\text { Çeşit ve çeşit } \\
\text { adayları }\end{array}$ & $\begin{array}{c}\text { Meyve eni } \\
(\mathrm{cm})\end{array}$ & $\begin{array}{c}\text { Meyve boyu } \\
(\mathrm{cm})\end{array}$ & $\begin{array}{c}\text { Meyve kabuk } \\
\text { kalınlığ }(\mathrm{mm})\end{array}$ & $\begin{array}{c}\text { Çekirdek evi } \\
\text { eni }(\mathrm{cm})\end{array}$ & $\begin{array}{c}\text { Çekirdek evi } \\
\text { boyu }(\mathrm{cm})\end{array}$ \\
\hline Arıcan 97 & 31.33 & $21.50 \mathrm{a}$ & $9.78 \mathrm{a}$ & 7.66 & 21.66 \\
DH 8 & 31.00 & $21.33 \mathrm{a}$ & $11.14 \mathrm{a}$ & 8.66 & 20.66 \\
DH 6 & 31.66 & $21.83 \mathrm{a}$ & $6.06 \mathrm{c}$ & 8.33 & 23.33 \\
Balkız & 29.33 & $18.33 \mathrm{~b}$ & $7.88 \mathrm{~b}$ & 5.66 & 20.00 \\
\hline LSD \%5 & Ö.D & 3.7 & 1.2 & Ö.D & Ö.D \\
\hline
\end{tabular}

*DH: Dihaploid, Ö.D.: istatistiksel anlamda önemli değil.

Kestane kabağı çeşit ve çeşit adaylarının meyve kabuk rengi ve meyve eti renklerinin L*, a* ve b*, değerleri üzerine önemli farklılıkların olduğu görülmüştür (Çizelge 3). Çalışmada çeşit ve çeşit adaylarından 71.49-76.66 arasında meyve kabuk rengi L* değerleri elde edilmiştir. Meyve kabuk rengi a* değerlerine bakıldığında genellikle eksi değerler görülmesine rağmen 0.91 ile DH-6 çeşit adayı en yüksek a* değerini vermiştir. Aynı şekilde DH-6 çeşit adayı diğerlerine göre 16.98 ile en yüksek b değerini veren çeşit adayı olmuştur. Meyve eti rengi $L^{*}$ değerlerine bakıldığında, Balkız (69.25) ve Arıcan 97 (65.52) çeşitleri en yüksek $L^{*}$ değerlerini vermiştir. Meyve eti rengi a* değerleri incelendiğinde, DH-8 (25.74) ve Arıcan 97 (23.58)'den en yüksek veriler elde edilirken, en yüksek b* değerleri Arıcan 97 (70.52), Balkız (70.01) ve DH-8 (65.87)'de tespit edilmiştir. Meyvelerin rengini belirlemede Chroma Meter kullanılarak elde edilen $L^{*}, a^{*}, b^{*}$ değerleri önemli bilgiler vermektedir. $L^{*}$ değeri 0 ile 100 arasında değişmekte olup siyah ile beyaz arasındaki renklenmeyi açıklar. a* değeri pozitif değerler kırmızı-mor tonunu belirlerken, negatif değerler ise mavimsi-yeşil renkleri tanımlamaktadır. b* değerlerinde ise pozitif değerler sarı, negatif değerler ise maviyi gösterir (McGuire, 1992). Yanmaz ve ark. (2016), ülkenin farklı bölgelerinden topladıkları bal kabağı genotiplerinden meyve etinden 56.89-80.84 arasında $L^{*}$ değeri, -2.09-28.19 arasında a* değeri ve 28.73-70.05 arasında $b^{*}$ değeri elde etmişlerdir. Elde ettiğimiz renk değerleri yapılan çalışmalarla uyumluluk göstermektedir.

Çizelge 3. Kestane kabağı çeşit ve çeşit adaylarının meyve kabuk ve meyve eti renkleri

\begin{tabular}{lcccccc}
\hline Çeşit ve çeşit & \multicolumn{3}{c}{ Meyve kabuk rengi } & \multicolumn{3}{c}{ Meyve eti rengi } \\
adayları & $\mathrm{L}^{*}$ & $\mathrm{a}^{*}$ & $\mathrm{~b}^{*}$ & $\mathrm{~L}^{*}$ & $\mathrm{a}^{*}$ & $\mathrm{~b}^{*}$ \\
\cline { 2 - 7 } Arıcan 97 & 76.66 & $-3.38 \mathrm{~b}$ & $12.55 \mathrm{~b}$ & $65.52 \mathrm{ab}$ & $23.58 \mathrm{ab}$ & $70.52 \mathrm{a}$ \\
DH 8 & 72.51 & $-2.92 \mathrm{~b}$ & $11.41 \mathrm{~b}$ & $60.01 \mathrm{~b}$ & $25.74 \mathrm{a}$ & $65.87 \mathrm{ab}$ \\
DH 6 & 71.49 & $0.91 \mathrm{a}$ & $16.98 \mathrm{a}$ & $62.64 \mathrm{~b}$ & $16.65 \mathrm{c}$ & $61.05 \mathrm{~b}$ \\
Balk1z & 73.53 & $-2.94 \mathrm{~b}$ & $12.67 \mathrm{~b}$ & $69.25 \mathrm{a}$ & $21.14 \mathrm{~b}$ & $70.01 \mathrm{a}$ \\
\hline LSD \%5 & Ö.D & 2.23 & 3.26 & 8.65 & 3.52 & 7.05 \\
\hline
\end{tabular}

*DH: Dihaploid, Ö.D.: istatistiksel anlamda önemli değil.

\section{Sonuç}

Yapılan çalışma sonucunda Konya şartlarında ülkemizde ticari çeşit olarak tescil almış Arıcan 97 ve Balkız ticari çeşitleri ve 2 adet dihaploid çeşit adayı olan kestane kabaklarının verim ve meyve kalitesine ait özellikleri ilk defa belirlenmiştir. Elde edilen veriler ışığında, Konya Ovasında Arıcan 97 önemli bir ticari çeşit olarak karşımıza çıksa da çeşit adayı olarak nitelendirilen DH-6 genotipi verim ve meyve kalitesi yönünden önemli sonuçlar vermiştir. Bu durumda, DH-6 genotipinin Arıcan 97'ye alternatif bir çeşit olarak değerlendirilebileceği görülmüştür. Diğer taraftan, DH-6 genotipinin yapılacak olan melezleme 1slahı sonucunda bazı özelliklerinin geliştirilerek ülke ve bölge tarımına önemli katkı sağlayacağı düşünülmektedir. 


\section{Teşekkür}

$\mathrm{Bu}$ çalışmanın yürütülmesinde ve materyal temininde yardımcı olan S.Ü. Ziraat Fakültesi Bahçe Bitkileri Bölümü öğretim üyesi Prof. Dr. Ertan Sait KURTAR’a teşekkür ediyorum.

\section{Kaynakça}

Adubofuor, J., Amoah, I., \& Agyekum, P. B. (2016). Physicochemical properties of pumpkin fruit pulp and sensory evaluation of pumpkin-pineapple juice blends. Am J od. Food Sci Technol, 4(4), 89-96.

Aslan, İ., Balkaya, A., Karaağaç, O., Sarıbaş, Ş., \& Kurtar, E. S. (2019) Yerel kestane kabağı (Cucurbita maxima Duch.) çeșit adaylarının Samsun ilinde farklı lokasyonlarda verim unsurları ve meyve kalite özellikleri yönünden performanslarının incelenmesi. Yüzüncü Y Yl Üniversitesi Tarım Bilimleri Dergisi, 29(2), 318-329.

Babaoğlu, D., \& Türkmen, Ö. (2017). Some fruit characteristics of genotype of pumpkin (cucurbita moschata duchesne) with the origin of western anatolia. I Ĭdır Üniversitesi Fen Bilimleri Enstitüsü Dergisi, 7(4).

Balkaya, A., Kurtar, E. S., Yanmaz, R., \& Özbakır, M. (2011). Karadeniz Bölgesi kestane kabağı (Cucurbita maxima) populasyonlarından seleksiyon islahı yoluyla geliştirilen çeşit adayları. Türkiye IV. Tohumculuk Kongresi. Bildiriler Kitabi-1, 17-22.

Balkaya, A., Özbakir, M., \& Kurtar, E. S. (2010). The phenotypic diversity and fruit characterization of winter squash (Cucurbita maxima) populations from the Black Sea Region of Turkey. African Journal of Biotechnology, 9(2), 152-162.

Bektemur, G., Yücel, N.K., Taşkın, H., Çömlekçioğlu, S., \& Büyükalaca, S. (2014). Effects of different genotypes and gamma ray doses on haploidization using irradiated pollen technique in squash. Turk $J$ Biol 38, 318-327.

Berber, M. (2009). Production of haploids in naked seed pumpkins (Cucurbita pepo L. var. styriaca) by pollination with irradiated pollen. MSc, Çukurova University, Adana, Turkey.

Blanco-Díaz, M. T., Font, R., Martínez-Valdivieso, D., \& Del Río-Celestino, M. (2015). Diversity of natural pigments and phytochemical compounds from exocarp and mesocarp of 27 Cucurbita pepo accessions. Sci Hortic (Amsterdam), 197, 357-65.

Conti, S., Villari, G., Amico, E., \& Caruso, G. (2015). Effects of production system and transplanting time on yield, quality and antioxidant content of organic winter squash (Cucurbita moschata Duch.). Scientia Horticulturae, 183, 136-143.

Dessì, M., Deiana, M., Day, B., Rosa, A., Banni, S., \& Corongiu, F. (2002). Oxidative stability of polyunsaturated fatty acids : effect of squalene. Eur J Lipid Sci Technol, 104, 506-12.

Ekincialp, A., Erdinç, Ç., Fuat, E., Demir, S., \& Şensoy, S. (2016). Farklı kabakgil türlerinde arazi koșullarında Arbusküler Mikorhizal Fungus (AMF), peynir altı suyu ve hümik asit uygulamalarının bitki gelişimi, verim ve kalite üzerine etkisi. Yüzüncü Yıl Üniversitesi Tarım Bilimleri Dergisi, 26(2), 274-281.

FAO (2018). Food and Agriculture Organization of the United Nations. http://www.fao.org/faostat/en/\#data/TP. Erişim Tarihi: 03 Nisan 2020.

Ferriol, M., Pico, B., \& Nuez, F. (2004). Morphological and molecular diversity of a collection of Cucurbita maxima Landraces. J of Amer Soc Hort Sci, 129(1), 60-69.

Kurtar, E. S., \& Balkaya, A. (2010). Production of in vitro haploid plants from in situ induced haploid embryos in winter squash (Cucurbita maxima Duchesne ex Lam.) via irradiated pollen. Plant Cell Tissue and Organ Culture 102, 267-277.

Kurtar, E. S., Balkaya, A., Özbakır, M., \& Ofluoglu, T. (2009). Induction of haploid embryo and plant regeneration via irradiated pollen technique in pumpkin (Cucurbita moschata Duchesne ex. Poir). African Journal of Biotechnology, 8 (21), 5944 - 5951.

Kurtar, E. S., Sarı, N., \& Abak, K. (2002). Obtention of haploid embryos and plants through irradiated pollen technique in squash (Cucurbita pepo L.). Euphytica 127, 335-344.

Kurtar, E.S., Balkaya, A., \& Kandemir, D. (2016). Evaluation of haploidization efficiency in winter squash (Cucurbita maxima Duch.) and pumpkin (Cucurbita moschata Duch.) through anther culture. Plant Cell, Tissue and Organ Culture, 127, 497-511. 
Kurtar, E.S., Balkaya, A., \& Ozbakir Ozer, M., (2018). Production of callus mediated gynogenic haploids in winter squash (Cucurbita maxima Duch.) and pumpkin (Cucurbita moschata Duch.). Czech Journal of Genetics and Plant Breeding, 54(1), 9-16.

McGuire, G. R., (1992). Reporting of objective color measurements. Hortscience, 27 (12), 1254-1255.

Medjakovic, S., Hobiger, S., Ardjomand-Woelkart, K., Bucar, F., \& Jungbauer, A. (2016). Pumpkin seed extract: Cell growth inhibition of hyperplastic and cancer cells, independent of steroid hormone receptors. Fitoterapia, 110, 150-156.

Nara, K., Yamaguchi, A., Maeda, N., Koga, H., \& Duchesne, C. (2009). Antioxidative activity of water soluble polysaccharide in pumpkin fruits (Cucurbita maxima Duchesne). Biosci Biotechnol Biochem,73(6), 1416-8.

Rabrenovi, B. B., Dimi, E. B., Novakovi, M. M., \& Te, V. V. (2014). The most important bioactive components of cold pressed oil from different pumpkin (Cucurbita pepo L.) seeds. LWT-Food Science and Technology, 55 (2), 521-527.

Seymen, M., Kurtar, E. S., Dursun, A., \& Türkmen, Ö. (2019). In Sustainable Agriculture: Assessment of Plant Growth Promoting Rhizobacteria in Cucurbitaceous Vegetable Crops. In Field Crops: Sustainable Management by PGPR (pp. 69-103). Springer, Cham.

TÜİK. (2018). Türkiye İstatistik Kurumu. https://biruni.tuik.gov.tr/medas/?kn=92\&locale=tr. Erişim Tarihi: 03 Nisan 2020.

Tzortzakis, N., Chrysargyris, A., \& Petropoulos, S. (2018). Phytochemicals Content and Health Effects of Cultivated and Underutilized Species of the Cucurbitaceae Family. Phytochemicals in Vegetables: A Valuable Source of Bioactive Compounds, 99.

Yanmaz, R., Akan, S., Salman, A., Tarım, T. G., Tarım, H. B. B. G., \& Müdürlüğü, H. İ. (2016). Türkiye'den toplanan kestane kabağı (Cucurbita maxima Duchesne) genotiplerinde meyve et rengi ile karotenoid miktarı arasındaki ilişkinin belirlenmesi. Bahçe (Özel sayl), 45(2), 55-60.

Yeşil, S. (2019). Some virus diseases of edible seed squash (Cucurbita pepo L.) in Aksaray province, Turkey. Yüzüncü Yıl Üniversitesi Tarım Bilimleri Dergisi, 29, 63-71. 